\title{
Impaired insulin-induced erythrocyte magnesium accumulation is correlated to impaired insulin-mediated glucose disposal in Type 2 (non-insulin-dependent) diabetic patients
}

\author{
G. Paolisso ${ }^{1}$, S. Sgambato ${ }^{2}$, D. Giugliano ${ }^{2}$, R. Torella ${ }^{2}$, M. Varricchio ${ }^{1}$, A.J. Scheen ${ }^{3}$, F. D'Onofrio ${ }^{2}$ and \\ P. J. Lefèbvre ${ }^{3}$ \\ ${ }^{1}$ Institute of Gerontology and Geriatrics, ${ }^{2}$ Institute of Medical Pathology, 1st Medical School, University of Naples, Italy, and \\ ${ }^{3}$ Division of Diabetes, Nutrition and Metabolic Disorders, Department of Medicine, University of Liège, Belgium
}

Summary. Plasma and erythrocyte magnesium levels were measured by atomic absorption spectrometry in 12 healthy subjects and 12 moderately obese patients with Type 2 (noninsulin-dependent) diabetes mellitus. Basal plasma and erythrocyte magnesium levels were significantly lower in diabetic patients than in control subjects. In vitro incubation in the presence of $100 \mathrm{mU} / 1$ insulin significantly increased magnesium erythrocyte levels in both control subjects $(p<0.001)$ and patients with diabetes $(p<0.001)$. However, even in the presence of $100 \mathrm{mU} / 1$ insulin, the erythrocyte magnesium content of patients with Type 2 diabetes was lower than that of control subjects. The in vitro dose-response curve of the effect of insulin on magnesium erythrocyte accumulation was shifted to the right when red cells of diabetic patients were used, with a highly significant reduction of the maximal effect. Such reduction of the maximal effect of insulin suggests that the impairment of insulin-induced erythrocyte magnesium accumulation observed in Type 2 diabetic patients results essentially from a post-recep- tor defect. In the diabetic patients, the $\Delta$ increase in erythrocyte magnesium levels (calculated as the net increase between basal and $100 \mathrm{mU} / 1$ insulin-induced erythrocyte magnesium levels) was negatively correlated with plasma insulin levels $(r=-0.86 ; p<0.001)$ and with body mass index $(r=-0.90 ; p<0.001)$; it was positively correlated with the glucose disappearance constant $\mathrm{K}_{\mathrm{g}}$ after intravenous glucose injection $(r=0.79 ; p<0.01)$, with the amount of glucose required to keep euglycaemia despite hyperinsulinaemia in a glucose clamp $(r=0.88 ; p<0.001)$, and with the metabolic clearance rate of glucose during the clamp $(r=0.82$; $p<0.001$ ). These results demonstrate that insulin-induced erythrocyte magnesium accumulation is impaired in patients with Type 2 diabetes and that such defect is correlated to impaired insulin-mediated glucose disposal in these patients.

Key words: Erythrocyte, Type 2 (non-insulin-dependent) diabetes, insulin, insulin-resistance, magnesium.
While low plasma levels of magnesium have been frequently reported in diabetes mellitus [1, 2], data on erythrocyte magnesium levels in diabetic patients are scarce; unchanged [3], increased [4] and decreased [5] red cell magnesium concentrations have been observed. We have recently reported that insulin induces a shift of magnesium from the plasma to the erythrocytes both in vivo and in vitro in man [6]. The aim of the present study was to investigate a possible relationship between impaired insulin-induced erythrocyte magnesium accumulation and the impaired insulin-mediated glucose disposal in Type 2 (non-insulin-dependent) diabetic patients.

\section{Subjects and methods}

\section{Subjects}

Twelve healthy subjects and twelve moderately obese patients with Type 2 diabetes volunteered for the study. Their main clinical and biological characteristics are provided in Tables 1 and 2. Mean age was similar but excess weight was significantly greater $(p=0.0027)$ in the diabetic patients than in the control subjects. No subject (control or diabetic) was taking any drug, except oral anti-diabetic agents, for at least three weeks before starting the experiment. All subjects gave informed consent, and the study was approved by the Ethical Committee of our institution. All were consuming a regular weight maintaining diet. In vivo studies were performed in the diabetic subjects only, while in vitro tests were done on samples collected from both healthy volunteers and diabetic patients. 
Table 1. Clinical and biological characteristics of normal subjects

\begin{tabular}{|c|c|c|c|c|c|c|c|}
\hline $\begin{array}{l}\text { Subject } \\
\text { number }\end{array}$ & Sex & $\begin{array}{l}\text { Age } \\
\text { (years) }\end{array}$ & $\begin{array}{l}\text { BMI } \\
\left(\mathrm{kg} / \mathrm{m}^{2}\right)\end{array}$ & $\begin{array}{l}\text { Basal plasma } \\
\text { glucose } \\
(\mathrm{mmol} / \mathrm{l})\end{array}$ & $\begin{array}{l}\text { Basal plasma } \\
\text { insulin } \\
(\mathrm{mU} / \mathrm{l})\end{array}$ & $\begin{array}{l}\text { Basal plasma } \\
\text { magnesium level } \\
(\mathrm{mmol} / 1)\end{array}$ & $\begin{array}{l}\text { Basal erythrocyte } \\
\text { magnesium level } \\
(\mathrm{mmol} / \mathrm{l})\end{array}$ \\
\hline 1 & $\mathbf{M}$ & 40 & 25 & 4.5 & 8 & 0.86 & 2.21 \\
\hline 2 & $\mathrm{~F}$ & 58 & 22 & 5.0 & 11 & 0.88 & 2.34 \\
\hline 3 & $F$ & 47 & 19 & 4.6 & 10 & 0.93 & 2.18 \\
\hline 4 & $\mathrm{~F}$ & 47 & 20 & 4.8 & 9 & 0.82 & 2.26 \\
\hline 5 & $\mathbf{M}$ & 73 & 24 & 5.1 & 16 & 0.88 & 2.41 \\
\hline 8 & $\mathrm{~F}$ & 46 & 23 & 4.4 & 10 & 0.92 & 2.31 \\
\hline 9 & M & 54 & 26 & 4.6 & 18 & 0.90 & 2.41 \\
\hline 10 & $\mathrm{~F}$ & 46 & 19 & 4.7 & 4 & 0.91 & 2.60 \\
\hline 11 & $\mathrm{M}$ & 41 & 21 & 4.6 & 9 & 0.90 & 2.51 \\
\hline 12 & $\mathbf{M}$ & 53 & 20 & 4.5 & 10 & 0.85 & 2.39 \\
\hline
\end{tabular}

${ }^{\mathrm{a}}$ All data are expressed as mean $\pm \mathrm{SEM}$. BMI $=$ Body mass index

Table 2. Clinical and biological characteristics of Type 2 (non-insulin-dependent) diabetic patients

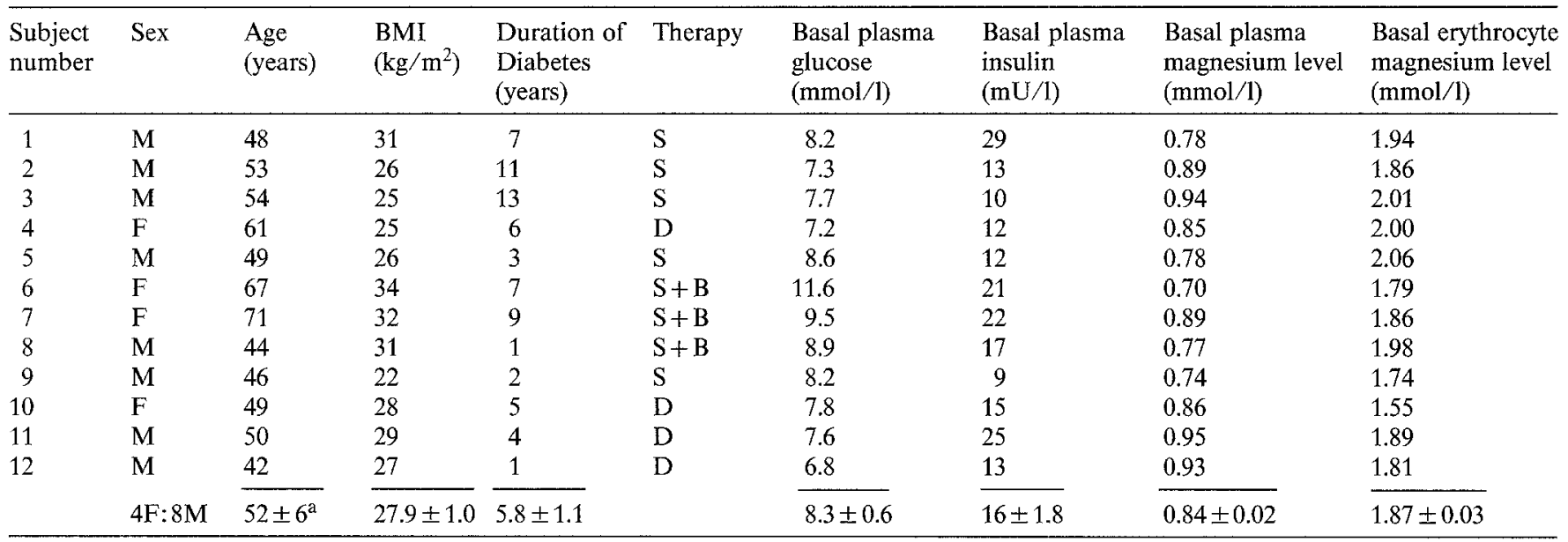

${ }^{a}$ All data are expressed as mean \pm SEM. Therapy is indicated as follows: $\mathrm{S}=$ Sulfonylureas; $\mathrm{B}=\mathrm{Biguanides} ; \mathrm{D}=\mathrm{Diet}$ alone. $\mathrm{BMI}=\mathrm{Body}$ mass index

\section{In vivo experimental protocols}

All diabetic patients were studied in the morning starting at 08.00-09.00 hours after a $12 \mathrm{~h}$ overnight fast. Two tests were performed in random order and separated by at least 1 day. In one experiment, an intravenous glucose tolerance test (IVGTT, $25 \mathrm{~g}$ in $3 \mathrm{~min}$ ) was performed. In the second experiment, a euglycaemic hyperinsulinaemic glucose clamp using the Biostator (Life Science Instr. Miles, Lab. Elkhart, Ind, USA) was used. In this test, performed with a fixed insulin infusion rate $\left(100 \mathrm{mU} \cdot \mathrm{kg}^{-1} \cdot \mathrm{h}^{-1}\right)$, a variable amount of glucose (as a $30 \%$ solution supplemented with a $0.26 \mathrm{mEq}$ $\mathrm{KCl}$ ) was infused to maintain normoglycaemia during all the experiment (120 min).

\section{In vitro experimental protocol}

In each fasted subject, a blood sample was collected into heparinised tubes. To separate the erythrocytes from plasma, the blood samples were centrifuged $(5000 \mathrm{rpm} \times 15 \mathrm{~min})$ and the precipitate washed at least three times using isotonic saline solution. Subsequently, the ery- throcytes were incubated for $90 \mathrm{~min}$ in a Krebs-Ringer buffer which had the following ionic composition (mmol/1): $\mathrm{NaCl}(122), \mathrm{KCl}(4.8)$, $\mathrm{CaCl}_{2}(2.5), \mathrm{MgCl}_{2}(1.2)$ and $\mathrm{NaHCO}_{3}(20)$. The solutions were continuously gassed with a mixture of $95 \% \mathrm{O}_{2}$ and $5 \% \mathrm{CO}_{2}$ to maintain a $\mathrm{pH}$ of 7.4 and the temperature kept at $37^{\circ} \mathrm{C}$. In a dose-effect curve study, insulin concentrations in the medium were $(\mathrm{mU} / \mathrm{l}): 0,10,50$, $100,500,1000$ and 10000 . After the incubation, the erythrocytes were treated as described below to determine their magnesium concentration.

\section{Analytical procedures}

Plasma glucose was determined immediately after completion of the experiment using a Beckman Auto-Analyzer (Beckman, Geneva, Switzerland). Plasma insulin was measured by radioimmunoassay (Bio-Data, Milan, Italy). Erythrocyte magnesium concentrations were determined after isolation of the erythrocytes from whole blood by centrifugation ( $5000 \mathrm{rpm}$ for $15 \mathrm{~min}$ ) and addition of $3 \mathrm{ml}$ deionised water to $2 \mathrm{ml}$ of precipitate. To $0.2 \mathrm{ml}$ of this mixture, $5 \mathrm{ml}$ of $0.75 \mathrm{mmol} / \mathrm{I}$ EDTA was added; after standing $30 \mathrm{~min}$, the solution was centrifuged and the supernatant was used for the assay. Plasma 
and erythrocyte magnesium concentrations were determined in triplicate by atomic absorption spectrophotometry using a Perkin-Elmer apparatus (Perkin-Elmer Co, Norwalk, Conn, USA).

\section{Materials}

Sodium chloride, potassium chloride, calcium chloride, magnesium chloride and sodium bicarbonate were obtained from Sigma (St. Louis, Mo, USA). Porcine insulin (Sigma) was prepared as a stable solution in $3 \mathrm{mmol} / 1 \mathrm{HCl}(1 \mathrm{mg} / \mathrm{ml})$ and added to the incubation medium just before use.

\section{Statistical analysis}

The glucose disappearance constant $\mathrm{K}_{\mathrm{g}}$ was calculated as the absolute value of the slope of the regression line relating the log of the plasma glucose to time in minutes from $10-60 \mathrm{~min}$ after the intravenous glucose injection, multiplied by 100 . The amount of glucose infused necessary to maintain the basal glycaemia despite insulin infusion (Glucose Infusion Rate or GIR) was calculated at 20-min intervals throughout the experiment and expressed as $\mathrm{mg} \cdot \mathrm{kg}^{-1} \cdot \mathrm{min}^{-1}$. After preliminary analysis of variance, the statistical comparisons were performed using unpaired Student's $t$-test or Wilcoxon signed rank test. Coefficients of correlation were calculated using the coefficient $r$ of Pearson. A $p<0.05$ was chosen as level of significance. All results are expressed as mean $\pm \mathrm{SEM}$.

\section{Results}

\section{Basal plasma and erythrocyte magnesium levels}

As shown in Tables 1 and 2, basal plasma and erythrocyte magnesium levels were significantly lower in diabetic patients than in control subjects: $0.84 \pm 0.02$ vs $0.88 \pm 0.01 \mathrm{mmol} / 1 \quad(p=0.031)$ and $1.87 \pm 0.03$ vs $2.37 \pm 0.04 \mathrm{mmol} / \mathrm{l}(p=0.001)$ respectively.

However, in the whole population studied, there were no significant correlations between basal plasma or erythrocyte magnesium levels on the one hand and basal plasma glucose or insulin concentrations on the other hand.

\section{Erythrocyte magnesium content: basal values and effect of insulin}

Incubation in the presence of $100 \mathrm{mU} / 1$ insulin significantly increased magnesium erythrocyte levels in both control subjects $(3.04 \pm 0.03$ vs $2.37 \pm 0.04 \mathrm{mmol} / 1$; $p<0.001)$ and patients with diabetes $(2.15 \pm 0.08$ vs $1.88 \pm 0.03 \mathrm{mmol} / \mathrm{l} ; p<0.001)$. However, even after incubation in the presence of insulin $(100 \mathrm{mU} / \mathrm{l})$, the erythrocyte magnesium content of patients with Type 2 diabetes was lower than that of control subjects (Fig. 1; $p<0.005$ ). Figure 2 illustrates the in vitro dose-response curve of the effect of insulin on magnesium erythrocyte
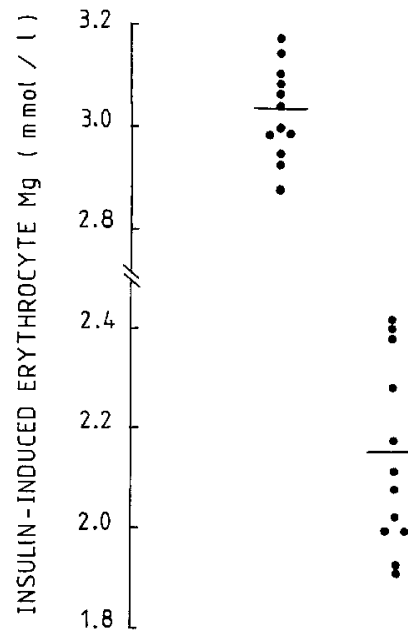

Fig. 1. Erythrocyte magnesium $(\mathrm{Mg})$ levels after incubation in the presence of $100 \mathrm{mU} / \mathrm{l}$ insulin. Data obtained in 12 healthy control subjects (left) are compared to those observed in 12 patients with Type 2 (non-insulin-dependent) diabetes (right)

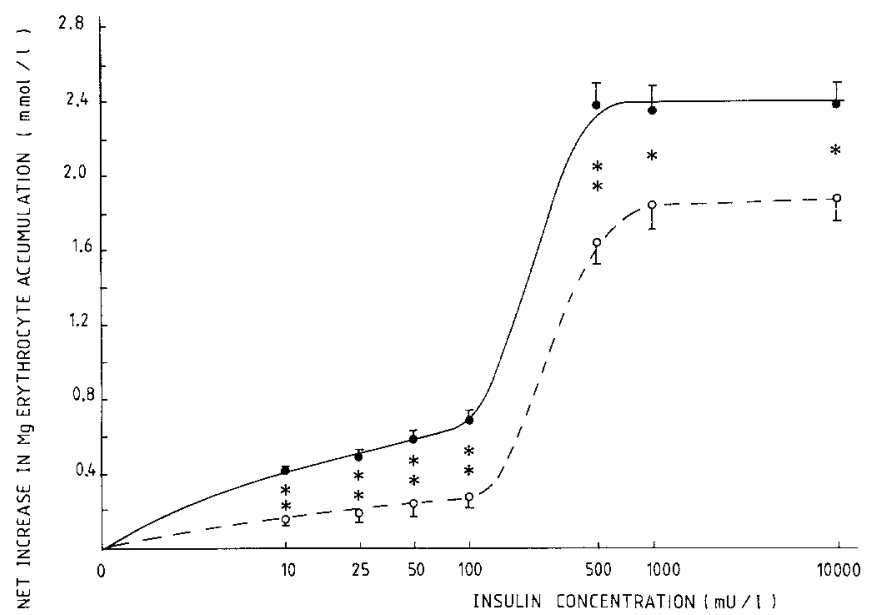

Fig. 2. Dose-response curves of the effect of insulin on magnesium erythrocyte accumulation. Data from 12 healthy control subjects (- ) and 12 patients with Type 2 diabetes $(\mathrm{O}-\mathrm{O})$. Results are expressed as mean \pm SEM. ${ }^{*}=p<0.01$ and ${ }^{* *}=p<0.001$

accumulation. In the healthy control subjects, as in the diabetic patients, erythrocyte magnesium levels increased while increasing the dose of insulin. In the patients with diabetes, however, the dose-response curve was shifted to the right. The maximal response was significantly less $(p<0.01)$ on erythrocytes from diabetic patients even at the highest concentrations tested, up to $10000 \mathrm{mU} / 1$.

\section{Correlations between the effect of insulin} on magnesium erythrocyte levels and various parameters of insulin sensitivity

In patients with diabetes, basal plasma insulin was slightly, but significantly higher, than in healthy control subjects: $16 \pm 1.8$ versus $10 \pm 1.2 \mathrm{mU} / 1(p=0.023)$. Similarly body weight was higher in the diabetic patients than in the control subjects (Tables 1 and 2). As shown in Figures 3 and 4, the $\Delta$ increase in erythrocyte magnesium levels (calculated as the net increase be- 


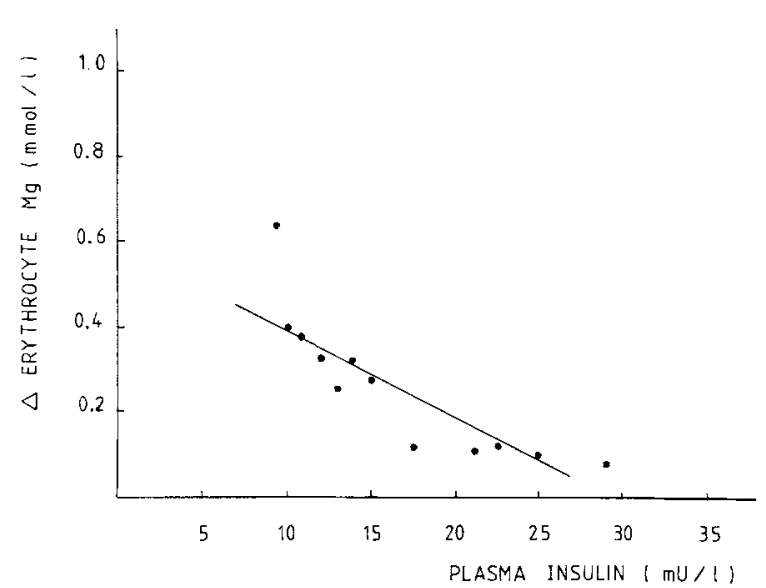

Fig.3. Correlation between $\Delta$ increase in erythrocyte magnesium levels (calculated as the net increase between basal and $100 \mathrm{mU} / 1$ insulin-induced erythrocyte magnesium levels) and basal plasma insulin in 12 patients with Type 2 diabetes mellitus $(r=-0.86$; $p<0.001$ )

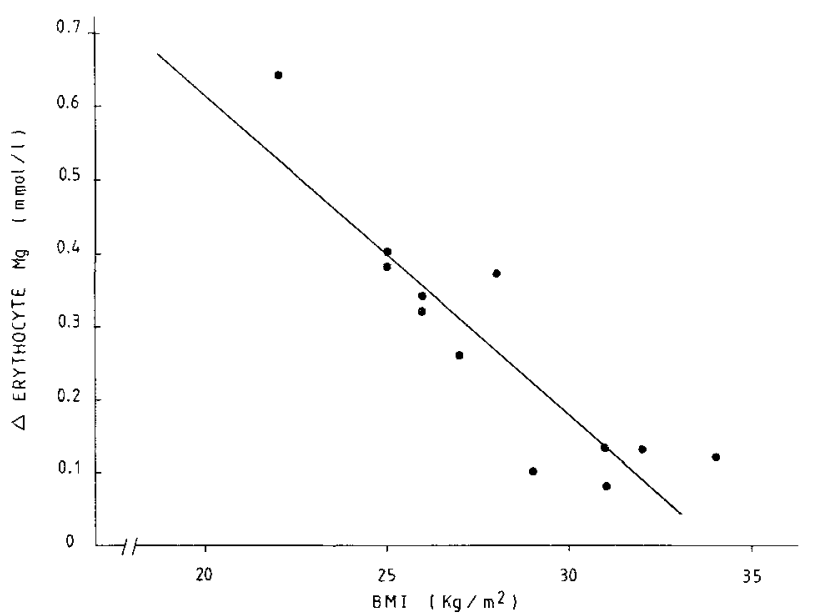

Fig. 4. Correlation between $\Delta$ increase in erythrocyte magnesium levels (calculated as the net increase between basal and $100 \mathrm{mU} / 1$ insulin-induced erythrocyte magnesium levels) and body mass index (BMI) in 12 patients with Type 2 diabetes mellitus $(r=-0.90$; $p<0.001)$

tween basal and $100 \mathrm{mU} / 1$ insulin-induced erythrocyte magnesium levels) was significantly and negatively correlated with both plasma insulin levels $(r=-0.86$; $p<0.001)$ and with body weight expressed as body mass index $(r=-0.90 ; p<0.001)$.

The glucose disappearance constant $\mathrm{K}_{\mathrm{g}}$ ranged between 0.41 and 1.02 in diabetic patients (Table 3 ). The $\Delta$ increase in erythrocyte magnesium levels was significantly and positively correlated with $\mathrm{K}_{\mathrm{g}}: r=0.79$; $p<0.01$ (Fig. 5).

In the euglycaemic glucose clamp, despite hyperinsulinaemia averaging about $115 \mathrm{mU} / 1$, plasma glucose was kept in the euglycaemic range: $6.1 \pm 0.4 \mathrm{mmol} / 1$ (coefficient of variation $4.3 \pm 0.8 \%$ ). In these conditions, the glucose infusion rate (GIR) during the last $60 \mathrm{~min}$ of the clamp ranged between 2.7 and $7.5 \mathrm{mg} \cdot \mathrm{kg}^{-1} \cdot \mathrm{min}^{-1}$

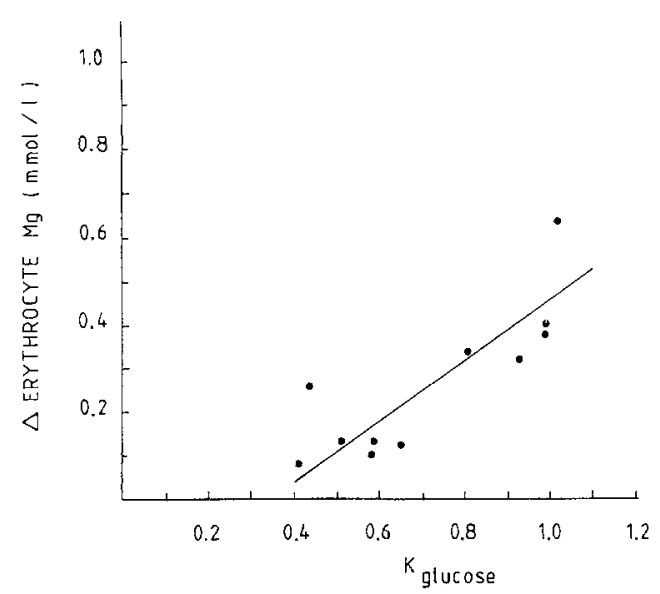

Fig.5. Correlation between $\Delta$ increase in erythrocyte magnesium levels (calculated as the net increase between basal and $100 \mathrm{mU} / 1$ insulin-induced erythrocyte magnesium levels) and the glucose disappearance constant $\mathbf{K}_{\text {glucose }}$ in 12 patients with Type 2 diabetes mellitus $(r=0.79 ; p<0.01)$

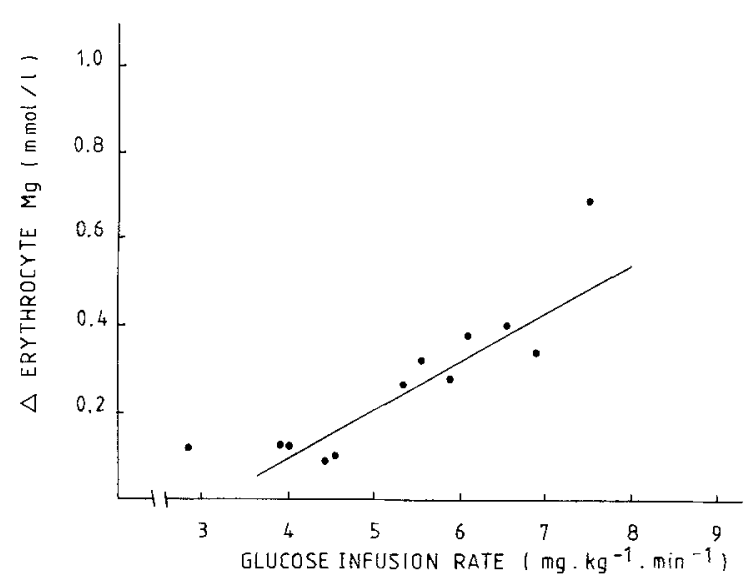

Fig. 6. Correlation between $\Delta$ increase in erythrocyte magnesium levels (calculated as the net increase between basal and $100 \mathrm{mU} / 1$ insulin-induced erythrocyte magnesium levels) and the glucose infusion rate during the euglycaemic hyperinsulinaemic glucose clamp in 12 patients with Type 2 diabetes mellitus $(r=0.88 ; p<0.001)$

(mean $5.5 \pm 0.3 \mathrm{mg} \cdot \mathrm{kg}^{-1} \cdot \mathrm{min}^{-1}$ ) (Table 3 ). As shown in Figure 6, this parameter was significantly and positively correlated with the in vitro insulin-induced $\Delta$ increase in erythrocyte magnesium levels: $r=0.88$; $p<0.001$. The metabolic clearance rate of glucose (GIR divided by steady-state plasma glucose levels) during the last $60 \mathrm{~min}$ of the clamp ranged between 2.4 and $6.7 \mathrm{ml} \cdot \mathrm{kg}^{-1} \cdot \mathrm{min}^{-1}$ (mean: $4.9 \pm 0.4 \mathrm{ml} \cdot \mathrm{kg}^{-1} \cdot \mathrm{min}^{-1}$ ) (Table 3). Again, this parameter was significantly and positively correlated with the insulin-induced $\Delta$ increase in erythrocyte magnesium levels: $r=0.82$; $p<0.001$.

In contrast, there was no significant correlation between basal plasma or erythrocyte magnesium levels and the various parameters of peripheral insulin sensitivity in the 12 diabetic patients studied. 
Table 3. Individual values of insulin-induced increase in erythrocyte magnesium $(\mathrm{Mg})$ level, Conard's $\mathrm{K}$ value $(\mathrm{K})$, glucose infusion rate $(\mathrm{M})$ and metabolic clearance rate of glucose (MCR) in Type 2 diabetic patients

\begin{tabular}{cllll}
\hline $\begin{array}{l}\text { Patient } \\
\text { number }\end{array}$ & $\begin{array}{l}\text { Insulin-induced } \\
\text { increase } \\
\text { in erythrocyte } \\
\text { Mg level } \\
\mathrm{mmol} / \mathrm{l}\end{array}$ & $\mathrm{K}_{\mathrm{g}}$ & $\begin{array}{l}\mathrm{M} \\
\left(\mathrm{mg} \cdot \mathrm{kg}^{-1}\right. \\
\left.\cdot \mathrm{min}^{-1}\right)\end{array}$ & $\begin{array}{l}\mathrm{MCR} \\
\left(\mathrm{ml} \cdot \mathrm{kg}^{-1}\right. \\
\left.\cdot \mathrm{min}^{-1}\right)\end{array}$ \\
\hline 1 & 0.08 & 0.41 & 4.4 & \\
2 & 0.32 & 0.93 & 5.6 & 4.1 \\
3 & 0.40 & 0.99 & 6.6 & 5.5 \\
4 & 0.38 & 0.99 & 6.2 & 5.9 \\
5 & 0.34 & 0.81 & 6.8 & 6.5 \\
6 & 0.12 & 0.65 & 4.0 & 3.7 \\
7 & 0.13 & 0.58 & 3.9 & 3.2 \\
8 & 0.13 & 0.51 & 2.7 & 2.4 \\
9 & 0.64 & 1.02 & 7.5 & 6.7 \\
10 & 0.37 & 0.47 & 5.8 & 5.7 \\
11 & 0.10 & 0.57 & 4.6 & 4.5 \\
12 & 0.26 & 0.44 & 5.7 & 5.2 \\
\hline & $0.27 \pm 0.05^{\text {a }}$ & $0.75 \pm 0.07$ & $5.5 \pm 0.34$ & $4.9 \pm 0.4$ \\
\hline
\end{tabular}

a All data are expressed as mean \pm SEM

\section{Discussion}

Magnesium, the most abundant intracellular divalent cation, is a necessary co-factor for many enzymes playing a key-role in cellular metabolism. Chronic magnesium deficiency has been hypothesised to be involved in the pathophysiology of numerous pathologies including hypertension [7], cardiac arrhythmias [8], acute myocardial infarction [9] and diabetes mellitus [1-5]. Particularly in diabetes mellitus, hypomagnesaemia has been suggested to be associated to macro- and microangiopathy [10, 11]. Furthermore, Mather et al. [12] reported a close relationship between hypomagnesaemia and poor diabetes control; in addition, low plasma magnesium levels are frequently observed during or after diabetic ketoacidosis [13].

We have recently reported that, in normal man, insulin induced opposite changes in plasma and erythrocyte magnesium concentration: a fall in plasma magnesium levels accompanied by a rise in erythrocyte magnesium concentration was observed in the course of an oral glucose tolerance test or during an euglycaemic hyperinsulinaemic glucose clamp [6]. Similarly, during in vitro incubations, erythrocyte magnesium levels were significantly increased by insulin $(100 \mathrm{mU} / \mathrm{l})$, an effect entirely abolished by ouabain [6]. From these observations, we suggested that insulin induced a shift of magnesium from the plasma to the erythrocytes both in vivo and in vitro. The present study confirms that insulin increases in vitro the erythrocyte magnesium levels in normal subjects and demonstrates that this effect is also present in the red cells of diabetic patients. However, the dose-response curve of this effect is shifted to the right when red cells from diabetic patients are com- pared to cells of healthy control subjects with a highly significant reduction of the maximal effect of insulin on erythrocyte magnesium accumulation. As classically recognised, such reduction in the maximal effect suggests that the impairment of insulin-induced erythrocyte magnesium accumulation observed in Type 2 diabetic patients mainly results from a post-receptor defect. Thus, such effect may be part of the insulin resistance phenomenon classically observed in this type of patients. This hypothesis is supported by the fact that the ability of insulin to increase magnesium erythrocyte levels in Type 2 diabetic patients is positively correlated with parameters of insulin sensitivity such as the glucose disappearance constant after an IVGTT or the in vivo insulin-mediated glucose disposal during the course of a hyperinsulinaemic euglycaemic glucoseclamp, a finding close to that reported by Yajnik et al. [14]; interestingly, it is negatively correlated with both basal plasma insulin levels and excess body weight, two factors usually associated with insulin resistance. Our data also agree with those of Rosenbloom [15] who described a reduced fall in plasma magnesium during an oral glucose tolerance test in patients with diabetes. Furthermore, we have recently reported an impaired insulin-mediated erythrocyte magnesium accumulation in essential hypertension [7], a disease which is also characterised by a reduced insulin-induced glucose disposal during a euglycaemic hyperinsulinaemic glucose clamp [16].

On the other hand, magnesium may influence glucose homeostasis. In vitro studies ascribe to magnesium an important role in insulin action [17-18]. In vivo investigations performed in man and in animals suggest that insulin resistance may accompany hypomagnesaemia. Moles and McMullen [19] have suggested that hypomagnesaemia may cause insulin resistance during treatment of ketoacidosis. Durlach et al. [20] showed a condition of chronic magnesium deficiency to be able to reduce insulin sensitivity at target cell levels. More recently, Legrand et al. [21] reported that rats fed a low magnesium diet had a lower insulin response to both intravenous and oral glucose loads and a distinct reduction in oral glucose tolerance.

Therefore, cellular magnesium deficiency can potentially be both a cause and an effect of insulin resistance. One can hypothesise that magnesium being an essential co-factor for many enzymatic systems, especially for those utilising high energy phosphate bounds [22], magnesium cellular loss may sustain a defective glucose metabolism contributing to, and potentiating, the insulin resistance itself. Further studies are needed to investigate the potential interest of supplementing the diabetic diet by the cautious administration of magnesium salts.

Acknowledgments. This study was performed as a cooperative project between the Universities of Naples (Italy) and Liège (Belgium). We acknowledge the expert secretarial help of E. Vaessen-Petit. 


\section{References}

1. Jackson CE, Meier DW (1968) Routine serum magnesium analysis: correlation with clinical state in 5100 patients. Ann Int Med 69: 743-748

2. Mather HM, Nisbet JA, Burton GH, Poston GJ, Bland JM, Bailey PA, Pilkington TRE (1979) Hypomagnesemia in diabetes. Clin Chem Acta 95: 235-242

3. Levin GE, Mather HM, Pilkington TRE (1981) Tissue magnesium status in diabetes mellitus. Diabetologia $21: 131-134$

4. Vanroelen WF, Van Gaal LF, Van Rooy PE, De Leeuw IH (1985) Serum and erythrocyte magnesium levels in type 1 and type 2 diabetics. Acta Diabetol Lat 22: 185-190

5. Fujii S, Takemura T, Wada M, Akai T, Okuda K (1982) Magnesium levels in plasma, erythrocyte and urine in patients with diabetes mellitus. Horm Metab Res 14: 161-162

6. Paolisso G, Sgambato S, Passariello N, Giugliano D, Scheen A, D'Onofrio F, Lefèbvre PJ (1986) Insulin induces opposite changes in plasma and erythrocyte magnesium concentrations in normal man. Diabetologia 29: 644-647

7. Paolisso G, Passariello N, Sgambato S, Torella R, Buoninconti R, Varricchio M, D'Onofrio F (1987) Impaired insulin-mediated erythrocyte magnesium accumulation in essential hypertension. Clin Sci $73: 535-539$

8. Iseri LT, French JH (1984) Magnesium: nature's physiologic calcium blocker. Am Heart J 108: 188-193

9. Dycknerr T (1980) Serum magnesium in acute myocardial infarction. Acta Med Scand 207: 59-66

10. McNair P, Christiansen C, Madsbad S, Lauritzen E, Faber O, Binder C, Transbøl I (1978) Hypomagnesemia, a risk factor in diabetic retinopathy. Diabetes 27: 1075-1077

11. Anonymous (1979) Hypomagnesaemia and diabetes retinopathy. Lancet I: 762

12. Mather HM, Levin GE, Nisbet JA, Hadley LA-A, Oakley NW, Pilkington TRE (1982) Diurnal profiles of plasma magnesium and blood glucose in diabetes. Diabetologia 22:180-183

13. Martin HE, Wertman M (1947) Serum potassium, magnesium and calcium levels in diabetic acidosis. J Clin Invest 26:217-228
14. Yajnik CS, Smith RF, Hockaday TDR, Ward NI (1984) Fasting plasma magnesium concentrations and glucose disposal in diabetes. Br Med J 288: 1032-1034

15. Rosenbloom AL (1977) Serum calcium and magnesium decline during oral glucose tolerance testing in children and adolescents with preclinical diabetes mellitus less than in normals. Metabolism 26: 1033-1039

16. Ferrannini E, Buzzigoli G, Bonadonna R, Giorico MA, Oleggini M, Graziadei L, Pedrinelli R, Brandi L, Bevilacqua S (1987) Insulin resistance in essential hypertension. N Engl J Med 317: 350-357

17. Lostroh AJ, Krahl ME (1974) Magnesium, a second messenger for insulin: ion translocation coupled to transport activity. Adv Enzyme Regul 12: 73-81

18. Sanui H, Rubin AH (1978) Membrane bound and cellular cationic changes associated with insulin stimulation of cultured cells. $J$ Cell Physiol 96: 265-278

19. Moles KW, McMullen JK (1982) Insulin resistance and hypomagnesaemia: case report. Br Med J 285: 262

20. Durlach J, Rayssiguier Y (1983) Magnésium et glucides, I.Données cliniques et thérapeutiques. Magnesium 2: 192-224

21. Legrand C, Okitolonda W, Pottier AM, Lederer J, Henquin JC (1987) Glucose homeostasis in magnesium-deficient rats. Metabolism 36: 160-164

22. Wacker WEC, Parisi AF (1968) Magnesium metabolism. N Engl J Med 278: 658-663

Received: 2 May 1988

and in revised form: 28 October 1988

Prof. P.J. Lefèbvre

Diabetes, Nutrition and Metabolic

Disorders Unit

C. H. U. Sart Tilman (B35)

B-4000 Liège 1

Belgium 